\title{
Arbeidsmiljø og røyking som årsak til lungekreft: noen epidemiologiske betraktninger
}

\author{
Tom Kristian Grimsrud \\ Kreftregisteret, Institutt for epidemiologisk kreftforskning, Montebello, 0310 Oslo
}

\begin{abstract}
SAMMENDRAG
Lungekreft er en av de hyppigst forekommende og alvorligste kreftsykdommene i verden. Etter den voldsomme økningen i sigarettforbruket i første halvdel av dette århundret har røykevanene inntatt en dominerende plass blant årsakene til lungekreft, mens yrkeseksponeringer er regnet for å være den nest viktigste årsak. Lungekreft er den vanligste yrkesbetingete kreftsykdom i Norge. Røykevanene er en potensiell confounder i vurderingen av yrkesmessige årsaker til lungekreft, men både teoretiske betraktninger og gjennomførte studier tyder på at problemet er relativt lite. Samvirkning mellom røykevaner og yrkeseksponering er best beskrevet når det gjelder asbeststøv og radon, og ser ut til å følge et multiplikativt mønster. For andre eksponeringer er forholdet mer ufullstendig belyst. Andelen lungekrefttilfeller som tilskrives yrkeseksponering, kan være betydelig i yrkesgrupper eller geografiske områder hvor kreftfremkallende stoffer har vært i utstrakt bruk.
\end{abstract}

\section{Grimsrud TK. Occupational exposures and smoking as causes of lung cancer: Some epidemiological considerations. Nor J Epidemiol 1995; 5 (2): 121-127.}

\section{ENGLISH SUMMARY}

Lung cancer is one of the the most common and most serious cancer diseases in the world. The enormous increase in cigarette consumption during the first half of this century made smoking the dominating cause of lung cancer. Occupational exposures are considered to be the second most important cause. Lung cancer is the most frequent occupational cancer in Norway. Smoking is a potential confounder in the study of occupational lung cancer. Theoretical and empirical considerations do however indicate that the problem is of minor magnitude. Interaction between smoking and occupational exposures is described for asbestos and radon and appears to follow a multiplicative pattern. Interaction with other occupational exposures is less well studied. The proportion of lung cancer cases attributable to occupational factors can be significant in certain occupations and geographical regions.

\section{INNLEDNING}

I vårt århundre er det få sykdommer som har endret seg i samme grad med hensyn til årsak og utbredelse som lungekreft. Fra å være en meget sjelden sykdom hvor yrke var eneste kjente årsak, er lungekreft i dag en av de vanligste og alvorligste kreftsykdommene $\mathrm{i}$ verden (1). I Norge er sykdommen den 3. hyppigste kreftsykdom både blant kvinner og menn. Kreftregisterets tall for relativ overlevelse 5 år etter at diagnosen ble stilt, viser at prognosen var nesten like dårlig på slutten av 1980-tallet som 30 år tidligere, til tross for betydelige fremskritt $\mathrm{i}$ behandlingen av en del andre former for kreft (Figur 1).
Det er utført mange epidemiologiske studier av lungekreft, og årsaksforholdene er relativt godt kartlagt. I land der tobakksrøyking har vært vanlig i mange år, er røyking den dominerende årsak. Det er anslått at mellom 80 og 90 prosent av tilfellene ville vært unngått dersom eksponering for tobakksrøyk ikke hadde skjedd. Eksponeringer i arbeidslivet er regnet for å være den nest viktigste årsak (2). Lungekreft er regnet for å være den hyppigste yrkesbetingete kreftsykdom i Norge (3). Denne artikkel vil belyse noen sider ved kartleggingen av disse sentrale årsakene. 


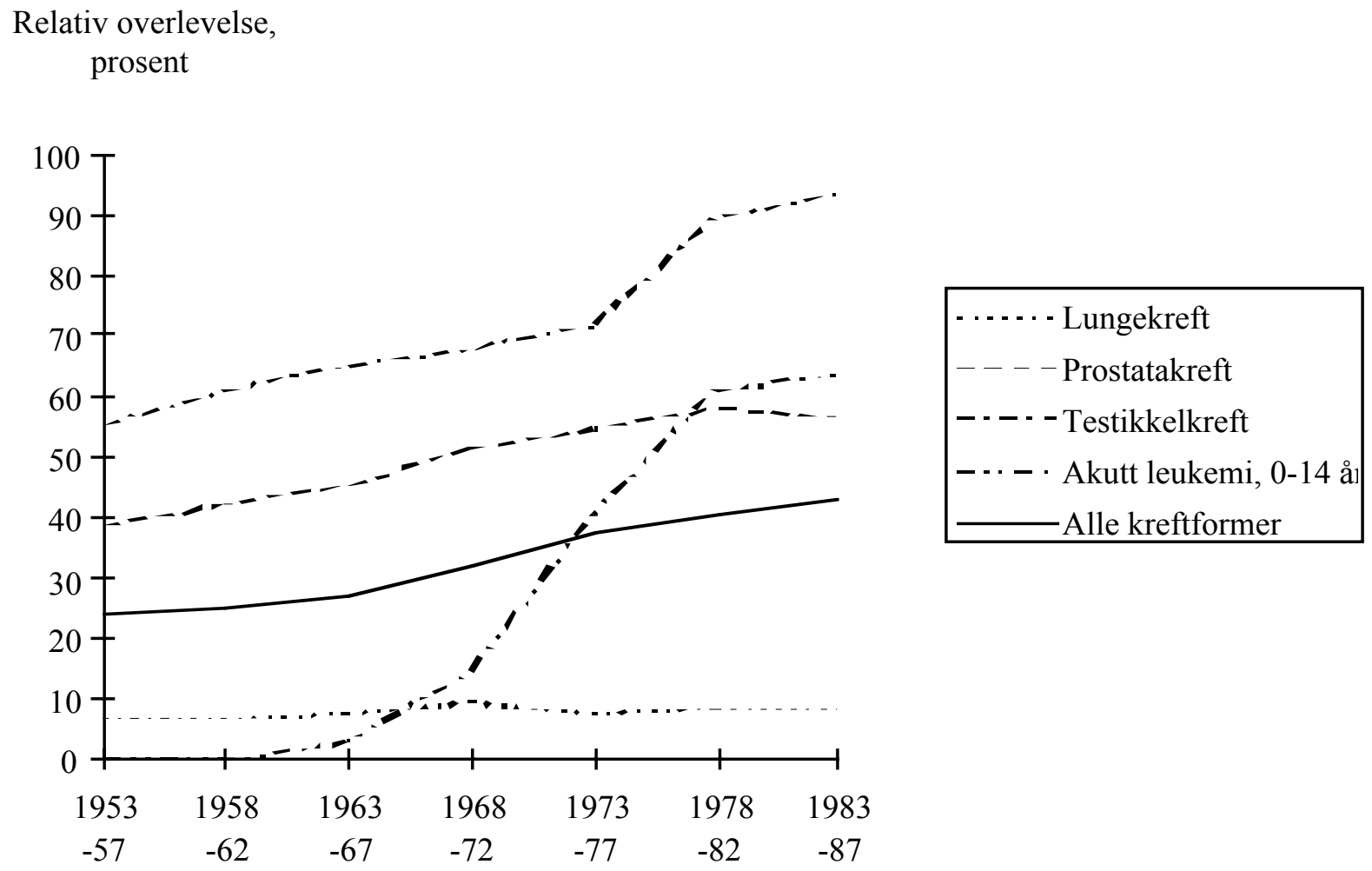

Diagnoseperiode

Figur 1: Relativ overlevelse for en del kreftformer hos menn 5 år etter at diagnosen er stilt.

\section{YRKESMESSIGE ÅRSAKER}

Yrkesmessige årsaker til lungekreft var lenge de eneste som var omtalt i medisinsk litteratur. Allerede på 1530-tallet beskrev den sveitsiske legen Paracelsus en tærende lungesykdom som rammet gruvearbeidere i Erzgebirge i Bøhmen. På 1870-tallet ble det klart at det dreide seg om en malign sykdom, og enda senere fant man ut at sykdommen hadde sammenheng med radioaktive spaltningsprodukter fra malm som inneholdt radium og uran.

Før sammenhengen mellom røyking og lungekreft ble endelig klarlagt, hadde man mistanke om at lungekreft også kunne skyldes yrkeseksponeringer som asbeststøv, krom-forbindelser, og eksponeringer ved gassverk og nikkelraffinerier. I løpet av de siste 40 årene er flere av disse sammenhengene bekreftet, mens en rekke andre stoffer er kommet i søkelyset som mulig kreftfremkallende. FNs internasjonale kreftforskningssenter i Lyon (IARC) klassifiserer de kreftfremkallende stoffene avhengig av den dokumentasjon som foreligger (kjemiske og toksikologiske forhold, cellestudier, dyrefors $ø \mathrm{k}$ og human-epidemiologiske undersøkelser). De stoffene som i 1987 ble ansett som kreftfremkallende eller mulig kreftfrem- kallende, er presentert i tabell 1 (4). I tillegg er en rekke yrkesaktiviteter vurdert å gi økt risiko for lungekreft.

Tabell 1: Kjente og mulige lungekarsinogene stoffer (etter IARC 1987) (4).

Kjente karsinogener (gruppe 1)

arsenforbindelser

asbeststøv

bis-klorometyl-eter

seksverdig krom

nikkelforbindelser

polysykliske aromatiske hydrokarboner (PAH)

radon

vinylklorid

Sannsynlige karsinogener (gruppe 2A)

akrylonitril

beryllium

kadmium

formalin

Mulige karsinogener (gruppe 2B)

acetaldehyd

syntetiske mineralfibre

silika

sveiserøyk 
I retrospektive undersøkelser av sammenhengen mellom yrke og kreft er det ofte vanskelig å skaffe detaljerte opplysninger om eksponeringer, både kvalitativt og kvantitativt. I mange tilfeller tar man utgangspunkt $\mathrm{i}$ bedriftsarkiver eller medlemsregistre fra fagforeninger, slik at det foreligger begrensete opplysninger om forholdene ved arbeidsplassen. Lønns- og personalarkiver kan som regel gi opplysninger om avdeling, jobbkategori, skiftforhold og formannsområde. I noen undersøkelser har man tilgang til resultater fra stasjonære målinger i arbeidsatmosfæren, eller enda bedre, personbårne målinger, eller registrering av opptak eller utskillelse. Som regel foreligger det likevel en mangel på pålitelige og representative eksponeringsmål, noe som gir risiko for feilklassifisering av eksponering. Det gjør vurderingene usikre og svekker muligheten til å påvise sammenhenger mellom eksponering og sykdom.

Retrospektive kohortundersøkelser er den vanligste form for studie av yrke og kreft. I slike undersøkelser blir forekomsten eller dødeligheten i en eksponert gruppe sammenlignet med den forventete forekomst i en referansegruppe, som gjerne er nasjonal, regional eller bedriftsintern. Et problem i den sammenheng er at sammenligningsgruppen sjelden er helt ueksponert, men består av personer som har vært utsatt både for den aktuelle eksponering og andre typer påvirkning.

De arbeidstakere som inngår i selve undersøkelsen, kan på sin side også ha vært utsatt for andre yrkeseksponeringer enn dem som er i søkelyset, både før, under og etter det aktuelle arbeidsforholdet. I tillegg kan levesett og levekår innvirke på kreftrisikoen. Det varierer fra undersøkelse til undersøkelse i hvilken grad slike mulige medvirkende faktorer er tatt hensyn til ved beregning av risiko. Røykevanene er her $\mathrm{i}$ en særstilling fordi det er en særdeles sterk risikofaktor for lungekreft. Hvilke forsiktighetsregler dette krever i tolkningen av resultatene, omtales senere i artikkelen.

\section{TOBAKK OG LUNGEKREFT}

Etter at man begynte å fremstille sigaretter maskinelt, skjøt forbruket i været som aldri før, spesielt i europeiske land og i Nord-Amerika. Rundt 20 år senere registrerte man en stigning $\mathrm{i}$ insidens og dødsfall av lungekreft som verden tidligere ikke hadde sett maken til for noen kreftform. På 25 år, fra 1922 til 1947, steg det årlige absolutte antall dødsfall av lungekreft i England og Wales med en faktor på 15 . Omregnet til aldersstandardiserte rater registrerte man at dødeligheten av lungekreft blant menn var 10 ganger større i perioden 1936-39 enn i perioden 1901$20(5)$.

Så sent som på 1950-tallet holdt man mulighetene åpne for at økningen i lungekreft kunne skyldes den generelle luftforurensning. I årene mellom 1950 og
1955 ble sammenhengen med sigarettrøyking avklart etter fremlegging av flere og bedre epidemiologiske undersøkelser. Røyking og lungekreft er i dag så nøye knyttet til hverandre at forekomsten av lungekreft i epidemiologiske studier benyttes som en indikator på røykevanene i befolkningen $(6,7)$.

I en vurdering av de kreftfremkallende egenskapene ved tobakksrøyk peker IARC på at risikoen for lungekreft i særlig grad varierer med 3 forhold: 1) hvilken type tobakk som røykes (sigaretter farligere enn sigarer og pipe), 2) varigheten av røykingen, og 3 ) mengden tobakk som røykes (1). Varigheten er en avgjørende faktor for flere av de alvorlige kroniske sykdommene som er knyttet til røyking. Den bestemmes blant annet av alder ved røykestart. Basert på den store engelske undersøkelsen av dødelighet blant britiske leger anslo Peto og Doll at den overskytende insidensrate av lungekreft øker med en faktor på 20 og 100 ganger dersom røykingens varighet økes fra 15 år til henholdsvis 30 og 45 år (8). Andre undersøkelser har vist en noe svakere risikoøkning med økende varighet.

Den relative risiko for å utvikle lungekreft hos en "stor-røyker" (med forbruk på mer enn 20 sigaretter daglig) ligger i forskjellige undersøkelser rundt 10 til 20 ganger risikoen til en som aldri har røykt. En slik risikoøkning er også funnet i norske undersøkelser (tabell 2) (9-11).

\section{RØYKING SOM CONFOUNDER I EPIDEMIO- LOGISKE LUNGEKREFTUNDERSØKELSER}

De fleste tilfeller av lungekreft i yrkesepidemiologiske studier inntreffer blant røykere. Risikoen for lungekreft er sterkt forhøyet ved et stort tobakksforbruk og langvarig røyking, og risikoen er høyere enn de fleste yrkesbetingete risikoer man har registrert. Det er derfor ikke unaturlig å spørre seg om det i det hele tatt er mulig å foreta meningsfulle studier over sammenhengen mellom lungekreft og miljøfaktorer uten samtidig å se på røykevanene. Man møter ikke sjelden påstanden om at en overhyppighet av lungekreft innenfor en yrkesgruppe eller blant eksponerte arbeidstakere helt eller delvis skyldes at det er en større andel røykere blant arbeidstakerne, og at de røyker mer enn det som er tilfelle i sammenligningsgruppen.

I epidemiologiske studier vil man ofte oppleve at røykevanene kan være ujevnt fordelt. Når en slik alternativ og selvstendig bidragende årsaksfaktor er skjevfordelt $\mathrm{i}$ forhold til den eksponering som er i søkelyset, snakker man om en confounder. Det er da av stor interesse å kunne si noe om i hvor stor grad skjevfordelingen av røykevanene kan påvirke resultatet, og hvilke forbehold som må tas når funnene skal tolkes.

Dette tema er belyst flere ganger i løpet av de siste 15-20 årene, både teoretisk og empirisk. Olav 
Axelson har foretatt teoretiske beregninger over hva ulikheter $\mathrm{i}$ andelen røykere kan bety for forekomsten av lungekreft (12). Han beregnet lungekreft-raten i hypotetiske befolkningsutvalg bestående av "ikkerøykere", "moderat-røykere" og stor-røykere" etter følgende formel

$$
\mathrm{I}=\mathrm{I}_{0} \cdot \mathrm{P}_{0}+\mathrm{I}_{0} \cdot \mathrm{R}_{\mathrm{M}} \cdot \mathrm{P}_{\mathrm{M}}+\mathrm{I}_{0} \cdot \mathrm{R}_{\mathrm{S}} \cdot \mathrm{P}_{\mathrm{S}}
$$

der I er insidensraten i den aktuelle befolkningsgruppe; $\mathrm{I}_{0}$ er insidensen blant ikke-røykere, $\mathrm{R}_{\mathrm{M}}$ og $\mathrm{R}_{\mathrm{S}}$ er den relative lungekreftrisiko for røykere med henholdsvis moderat $(<20 \mathrm{sig} / \mathrm{d})$ eller stort forbruk $(20+\operatorname{sig} / d)$ i forhold til ikke-røykere; og $\mathrm{P}_{0}, \mathrm{P}_{\mathrm{M}}$ og $\mathrm{P}_{\mathrm{S}}$ er andelen henholdsvis ikke-røykere, moderat-røykere og stor-røykere i befolkningsutvalget. $R_{M}$ og $R_{S}$ er $i$ beregningene satt til 10 og 20 .

Innenfor de ytterpunkter som røykevanene den gang varierte mellom i svenske arbeidstakergrupper, fant Axelson at forekomsten av lungekreft ikke kunne forventes å avvike med mer enn $45 \%$ opp eller ned $\mathrm{i}$ forhold til normalbefolkningen. På denne bakgrunn pekte han på at man bør være forsiktig med å trekke konklusjoner om yrkesmessig sammenheng når den relative risiko for gruppen er forhøyet med en faktor på 2 eller lavere (risk ratio) uten at det er korrigert for røykevaner. På den annen side kan større forskjeller i risiko neppe forklares med skjevheter i røykevanene (13).

Axelsons beregningsmodell tar ikke hensyn til mulige forskjeller $\mathrm{i}$ historiske røykevaner, og derved varigheten og mengden tobakk som er røykt. Den tar heller ikke hensyn til hvilken type tobakk som røykes eller ulik fordeling av røykevanene på tvers av aldersgruppene i befolkningsutvalgene. Det kan tenkes at visse bransjer eller bedrifter har hatt en rekruttering som har medført til dels store skjevheter mellom arbeidstakergruppen og en aktuell referansegruppe. Erfaringer fra epidemiologiske undersøkelser tyder imidlertid på at disse innvendingene ikke har så stor praktisk betydning.

I retrospektive kohortundersøkelser foreligger som regel ingen opplysninger om røykevanene. Men i andre typer undersøkelser, slik som pasient-kontrollundersøkelser, kan man skaffe seg tilgang til røykeopplysninger og beregne risiko med og uten korreksjon for røykevanene. I slike tilfeller viser det seg at effekten av korrigering som regel er relativt moderat. Siemiatycki har sett spesielt på confoundereffekten av røyking i et stort pasient-kontrollmateriale med kanadiske pasienter fra perioden 197985 (14). Han hadde muligheten til å foreta en mer detaljert korrigering enn det Axelson tok inn i sine teoretiske beregninger.

For å lette sammenligningen mellom beregnet risiko med og uten korreksjon, regnet Siemiatycki ut forholdet mellom det største risikoanslaget (teller) og det minste (nevner) for 25 yrkesgrupper. Det største avviket i yrkestilknyttet lungekreftrisiko ble funnet hos undervisningspersonell, der rateforholdet var på 1,62. Andelen storrøykere var da svært avvikende blant kontrollene innenfor denne yrkeskategori $(32,6 \%$ mot $58,2 \%)$. Blant de øvrige 24 yrkesgruppene var rateforholdet lavere enn 1,20. Siemiatycki kunne videre vise at man oppnådde bedre korreksjon med en gradert angivelse av røykevanene fremfor en todeling i aldri-røykere og personer som noen gang hadde røykt.

Effekten på beregnet lungekreftrisiko ved korrigering for røykevaner kan vi også finne i norske undersøkelser $(10,11,15)$. Resultatene er presentert $i$ tabell 3, og som man ser er avviket relativt lite. I Kjuus' store sykehusbaserte pasient-kontroll-studie fra 1986 presenteres ialt 60 beregninger av risk ratio hvor verdien er angitt med og uten korreksjon for røykevaner (10). Den største forskjell mellom risk ratioene var en faktor på 2,4 for sjømenn. I den beregningen var det ikke flere enn 9 kontrollpersoner og 18 pasienter, og risiko-estimatet var ikke signifikant på 5-prosent-nivå. Sjømenn er dessuten kjent for å ha relativt sterkt avvikende røykevaner i forhold til den øvrige befolkning (16). Blant de øvrige beregningene i Kjuus' undersøkelse var det bare 5 tilfeller hvor avviket var på mellom 1,50 og 1,71, og i de resterende 54 lå avviket lavere enn 1,5.

Det har i løpet av de siste tiårene skjedd endringer i fordelingen av røykevanene i den norske befolkning med en klar skjevfordeling mellom sosiale klasser. Ifølge Statens tobakkskaderåd er det 49\% dagligrøykere blant menn over 24 år med utdanning bare fra ungdomsskole, mens gjennomsnittet for menn i

Tabell 2. Relativ risiko for lungekreft hos storrøykere ( 20 sigaretter eller mer daglig) i forhold til aldri-røykere.

\begin{tabular}{|c|c|c|}
\hline Forfatter & Relativ risiko & Merknad \\
\hline Lund $1981^{(9)}$ & 18,2 & Menn, yrkesmessige eksponeringer ikke registrert \\
\hline Kjuus $1986^{(10)}$ & $13,2 *$ & Menn ansett som ueksponert yrkesmessig \\
\hline Kvåle $1986^{(11)}$ & 13,1 & Menn, justert for yrkesmessig eksponering \\
\hline
\end{tabular}

* Referansegruppen er her menn som røykte 0-9 sigaretter daglig. 13,2 representerer derfor en underestimering av røykeeffekten. 
samme alder uansett utdanning ligger på 38\% (gjennomsnittstall for årene 1991-93) (17). Den forventete forskjell i forekomst av lungekreft er beregnet med Axelsons metode, og det samme er gjort for en tenkt gruppe industriarbeidere der andelen dagligrøykere er satt til 60\%. Andel stor-røykere (mer enn 19 sigaretter daglig) settes til $30 \%$ av dagligrøykerne i hver av gruppene. Resultatene er fremstilt i tabell 4. Det er verdt å merke seg at det forventete avviket er mindre enn 1,50.

I de senere år har man i flere sammenhenger kunnet karakterisere eksponeringer med større grad av nøyaktighet enn tidligere. Da kan man, selv med manglende røykedata, uttale seg med større sikkerhet om yrkesbetinget risiko ved å studere endringen $\mathrm{i}$ risiko ved ulik grad av eksponering. Det er også foretatt avanserte studier for å finne bedre statistiske modeller som kan predikere forekomsten av lungekreft i forhold til røykevanene.

\section{SAMVIRKNING MELLOM TOBAKK OG YRKESEKSPONERING}

Den risikoøkning som observeres når personer er utsatt for kreftfremkallende stoffer $i$ arbeidslivet og samtidig er dagligrøykere, har vært viet en del oppmerksomhet. Begreper som ofte blir brukt i den forbindelse, er samvirkning, samspill eller interaksjon. Temaet er grundig behandlet av andre, og i denne sammenheng vil noen begreper og konklusjoner bli kommentert $(18,19)$.
Studiet av samvirkning mellom ulike faktorer har historisk sett først og fremst vært foretatt av toksikologer og farmakologer. I statistisk sammenheng betegner interaksjon et avvik fra en statistisk modell som datamaterialet søkes tilpasset til. For å bedre tilpasningen kan det bli nødvendig å innføre samspillsledd (interaksjonsledd) i modellen, fordi risikoen synes å bli en annen enn den forventete når eksponeringene opptrer samtidig (effektmodifisering). Blant ikke-statistikere blir begrepet interaksjon brukt mindre strengt, og ofte kan man oppleve at det knyttes nær opp til biologiske forklaringsmodeller.

I mange analyser er det vanlig å operere $\mathrm{i}$ en multiplikativ modell og angi sammenhengen mellom eksponering og sykdom med en form for relativ risiko. Når Saracci og Bofetta vurderer ulike grader av samspill (interaksjon), tar de utgangspunkt i risikoangivelse fra slike multiplikativ modeller, men bruker betegnelsen interaksjon i en litt videre betydning (19). De vurderer størrelsen av risikoen ved kombinert eksponering i forhold til risikoen hos helt ueksponerte, og angir i hvilken grad risikoøkningen ser ut til å følge et additivt eller multiplikativt mønster. Fremgangsmåten kan illustreres ved 2x2-tabellen og formlene nedenfor, der RR står for relativ risiko.

\begin{tabular}{|l|l|l|}
\hline & $\begin{array}{l}\text { Ueksponert } \\
\text { for faktor 1 }\end{array}$ & $\begin{array}{l}\text { Eksponert } \\
\text { for faktor 1 }\end{array}$ \\
\hline $\begin{array}{l}\text { Ueksponert } \\
\text { for faktor 2 }\end{array}$ & $\mathrm{RR}=1,00$ & $\mathrm{RR}_{1}$ \\
\hline $\begin{array}{l}\text { Eksponert for } \\
\text { faktor 2 }\end{array}$ & $\mathrm{RR}_{2}$ & $\mathrm{RR}_{1,2}$ \\
\hline
\end{tabular}

Tabell 3. Forholdet mellom risiko beregnet med og uten korreksjon for røykevaner i norske undersøkelser av yrkesbetinget lungekreft.

\begin{tabular}{|c|c|c|}
\hline Forfatter & Rate ratio & Kommentar \\
\hline Kjuus $1986 \mathrm{I}^{(10)}$ & 1,71 & $\begin{array}{l}\text { Største forskjell i eksponeringsgrupper med mer enn } 10 \text { pasienter } \\
\text { og } 10 \text { kontroller. }\end{array}$ \\
\hline Kjuus 1986 II $^{(15)}$ & 1,25 & Største forskjell blant asbesteksponerte. \\
\hline Kvåle $1986^{(11)}$ & 1,23 & $\begin{array}{l}\text { Forholdet mellom O/E-ratio korrigert og ukorrigert. Gjelder sikker } \\
\text { yrkeseksponering. Justert for alder, region og bosted (by/land). }\end{array}$ \\
\hline
\end{tabular}

Tabell 4. Fordeling av røykevaner og tilsvarende beregnet rate ratio for ulike befolkningsutvalg.

\begin{tabular}{lcccc}
\hline Befolkningsutvalg & $\begin{array}{c}\text { Andel ikke- } \\
\text { røykere }\end{array}$ & $\begin{array}{c}\text { Andel røykere med } \\
\text { forbruk }<20 \text { sig/d }\end{array}$ & $\begin{array}{c}\text { Andel røykere med } \\
\text { forbruk 20+ sig/d }\end{array}$ & Rate ratio \\
\hline Alle menn 25+ år & $62 \%$ & $27 \%$ & $11 \%$ & 1,00 \\
Ungdomsskole & $51 \%$ & $34 \%$ & $15 \%$ & 1,25 \\
Industriarbeidere & $40 \%$ & $42 \%$ & $18 \%$ & 1,49 \\
\hline
\end{tabular}


Følgende formel beskriver det Saracci og Bofetta benevner et enkelt additivt mønster uten interaksjon:

$$
\mathrm{RR}_{1,2}=\mathrm{RR}_{1}+\mathrm{RR}_{2}-1 .
$$

Dersom $\mathrm{RR}_{1,2}$ er større enn dette, foreligger etter Saracci og Bofetta en positiv interaksjon, hvorav et særtilfelle foreligger når dataene passer $\mathrm{i}$ et multiplikativt mønster:

$$
\mathrm{OR}_{1,2}=\mathrm{OR}_{1} \cdot \mathrm{OR}_{2} .
$$

Alle grader av interaksjon karakteriseres så i forhold til disse to mønstre.

Når det gjelder lungekreft, er graden av samvirkning mellom røyking og yrkeseksponering best beskrevet for asbest og radon. Saracci og Bofetta peker på at de fleste undersøkelser av samvirkning mellom asbest og tobakk passer tilnærmet inn i en multiplikativ modell, men at bildet er sammensatt. Resultatene fra undersøkelser av radon og røyking passer også inn i en multiplikativ modell når det gjelder urangruvearbeidere. Resultater fra andre typer gruver er mer varierende. For andre lungekarsinogener er samvirkning med tobakk på langt nær så godt beskrevet som for asbest og radon.

Det er viktig i denne sammenheng å være klar over at tilpasning til en statistisk modell ikke uten videre kan knyttes til en bestemt biologisk forklaringsmodell. En biologisk mekanisme kan ofte være forenlig med flere ulike statistiske modeller.

\section{TILSKRIVBAR ANDEL}

Mange epidemiologiske studier presenterer anslag over hvor stor del av lungekrefttilfellene som kunne vært unngått, dersom man eliminerte en av de kjente kreftfremkallende påvirkningene. Ved beregning av slik tilskrivbar andel for en faktor er det vanlig å forutsette at de andre risikofaktorene holdes på samme nivå. Ved multifaktorielle årsaksforhold må denne type statistiske modeller tolkes med forsiktighet, men de kan gi et visst inntrykk av betydningen av enkeltfaktorene. Den tilskrivbare andel for tobakk er som tidligere nevnt anslått til å ligge på mellom $80 \%$ og $90 \%$, noe lavere for kvinner enn for menn p.g.a. ulikheter i historiske røykevaner.

I en oversiktsartikkel angir Vineis og Simonato at andelen tilfeller som tilskrives yrke varierer mellom $1 \%$ og $40 \% \mathrm{i}$ industrialiserte land (20). I to av de norske undersøkelsene som tidligere er referert, er det utført tilsvarende beregninger. Resultatene fremgår av tabell $5(11,21)$.

Det er flere forhold som har betydning for den beregnete størrelse på disse andelene. De vil blant annet variere med hvor utbredt kreftfremkallende stoffer er på arbeidsplassene, eller i hvilken grad man har lykkes $\mathrm{i}$ å beskrive eksponeringene på en måte som er representativ. Av den grunn kan det forsåvidt være relativt uinteressant å sammenligne resultater fra ulike undersøkelser.

Som en konklusjon kan man peke på følgende: Selv om røyking fører til en høy individuell risikoøkning og står for en dominerende tilskrivbar andel av lungekrefttilfellene, er arbeidsmiljøfaktorer fortsatt en viktig årsak til lungekreft i befolkningen. En sterk sammenheng mellom yrkeseksponering og lungekreft vil fortsatt kunne påvises uten kjennskap til individuelle røykevaner, men dersom den beregnete risikoøkning er liten, vil en vurdering av røykevanene være avgjørende for tolkningen av resultatet.

\begin{tabular}{|c|c|c|c|c|}
\hline Forfatter & $\begin{array}{c}\text { Tilskrivbar } \\
\text { andel }\end{array}$ & $\begin{array}{l}\text { Krefttilfeller } \\
\text { fra perioden }\end{array}$ & $\begin{array}{c}\text { Geografisk } \\
\text { område }\end{array}$ & Kommentarer \\
\hline Kvåle $1986^{(11)}$ & $14-27 \%$ & $1968-78$ & $\begin{array}{l}\text { landsrepre- } \\
\text { sentativt } \\
\text { utvalg }\end{array}$ & $\begin{array}{l}\text { Andelen avhenger av hva man anser } \\
\text { som yrkeseksponering. Justert for } \\
\text { røykevaner, alder, region og bosted i } \\
\text { by- eller landkommune. }\end{array}$ \\
\hline $\begin{array}{l}\text { Kjuus } 1986 \\
\text { IIII }^{(21)}\end{array}$ & $22-47 \%$ & $1979-83$ & $\begin{array}{l}\text { Vestfold og } \\
\text { Telemark }\end{array}$ & $\begin{array}{l}\text { Andelen avhenger av hva man anser } \\
\text { som yrkeseksponering og hvilken } \\
\text { informasjonskilde som beregningene } \\
\text { bygger på (intervju eller jobbtittel). } \\
\text { Justert for røykevaner og bosted i by- } \\
\text { eller landkommune. }\end{array}$ \\
\hline
\end{tabular}

Tabell 5. Andelen lungekrefttilfeller som tilskrives yrkeseksponering i to norske undersøkelser. 


\section{REFERANSER}

1. International Agency for Research on Cancer. Tobacco Smoking. Lyon, France: IARC, 1986; IARC Monogr Eval Carcinog Risks Chem Humans, Vol 38.

2. Doll R, Peto R. The causes of cancer: Quantitative estimates of avoidable risks of cancer in the United States today. J Natl Cancer Inst 1981;66:1191-1308.

3. Lund E. Andel av nye krefttilfelle forårsaket av yrkesmessig eksposisjon. En gjennomgang av publiserte estimater. Tidsskr Nor Laegeforen 1983;103:2-4.

4. International Agency for Research on Cancer. Overall Evaluations of Carcinogenicity: An updating of IARC Monographs Volumes 1 to 42. Lyon, France: IARC, 1987; IARC Monogr Eval Carcinog Risks Chem Humans, Supplement 7.

5. Doll R, Bradford Hill A. Smoking and carcinoma of the lung. Preliminary report. Br Med J 1950; ii: 739-748.

6. Skov T, Sprøgel P, Engholm G, Frølund C. Cancer of the lung and urinary bladder in Denmark, 1943-87: A cohort analysis. Cancer Causes Control 1991; 2: 365-369.

7. Peto R, Lopez AD, Boreham J, Thun M, Heath C, Jr. Mortality from tobacco in developed countries: indirect estimation from national vital statistics. Lancet 1992; 339: 1268-78.

8. Peto R, Doll R. Keynote address: The control of lung cancer. I Mizell M, Correa P, eds. Lung cancer: Causes and prevention. New York: Verlag Chemie International, 1984: 1-19.

9. Lund E, Zeiner Henriksen T. Røking som risikofaktor for ulike kreftformer blant 26000 norske menn og kvinner. En kobling av et røkemateriale med Kreftregisteret over en 12 års periode. Tidsskr Nor Lageforen 1981; 101: 1937-1940.

10. Kjuus H, Skjærven R, Langård S, Lien JT, Aamodt T. A case-referent study of lung cancer, occupational exposures and smoking. I. Comparison of title-based and exposure-based occupational information. Scand J Work Environ Health 1986; 12: 193-202.

11. Kvåle G, Bjelke E, Heuch I. Occupational exposure and lung cancer risk. Int J Cancer 1986; 37: 185-193.

12. Axelson O. Aspects on confounding in occupational health epidemiology. Letter to the editor. Scand $J$ Work Environ Health 1978; 4: 98-102.

13. Axelson O. Aspects of confounding and effect modification in the assessment of occupational cancer risk. J Toxicol Environ Health 1980;1127-1131.

14. Siemiatycki J, Wacholder S, Dewar R, Cardis E, Greenwood C, Richardson L. Degree of confounding bias related to smoking, ethnic group, and socioeconomic status in estimates of the associations betwen occupation and cancer. J Occup Med 1988; 30: 617-625.

15. Kjuus H, Langård S, Skjærven R. A case-referent study of lung cancer, occupational exposures and smoking, II. Role of asbestos exposure. Scand J Work Environ Health 1986; 12: 203-209.

16. Baksaas I, Lund E, Skjerven JE, Langård S, Vellar OD, Aarø LE. Kreft blant sjømenn. Tidsskr Nor Lageforen 1983; 103: 2317-2320.

17. Statens tobakkskaderåd. Opp i røyk? Om tobakksbruk i Norge gjennom 20 år 1973-93. Oslo, Statens tobakkskaderåd, 1994: 8-13.

18. Saracci R. The interactions of tobacco smoking and other agents in cancer etiology. Epidemiol Rev 1987; 9: 175-193.

19. Saracci R, Bofetta P. Interactions of tobacco smoking with other causes of lung cancer. I Epidemiology of lung cancer. New York: Marcel Dekker, Inc, 1994: 465-493.

20. Vineis P, Simonato L. Proportion of lung and bladder cancers in males resulting from occupation: A systematic approach. Arch Environ Health 1991; 46 :6-15.

21. Kjuus H, Langård S, Skjærven R. A case-referent study of lung cancer, occupational exposures and smoking, III. Etiological fraction of occupational exposures. Scand J Work Environ Health 1986; 12: $210-215$. 